\title{
A identidade religiosa na antroponímia de Marechal Cândido Rondon
}

\section{Religious identity on Marechal Cândido Rondon anthroponymy}

\author{
Márcia Sipavicius Seide \\ Universidade Estadual do Oeste do Paraná (UNIOESTE) campi Marechal Cândido \\ Rondon e Cascavel, Paraná, Brasil. \\ marciaseda4@hotmail.com
}

Resumo: Este artigo investiga a escolha de nomes por motivação religiosa em Marechal Cândido Rondon, município situado no oeste do estado do Paraná, com base em três corpora, um de 2012, coletado de relatos de alunos do $2^{\circ}$ ano de Letras; outro de 2013, de questionários aplicados a alunos do $4^{\mathrm{o}}$ ano de Letras; e uma amostra de certidões de nascimento - 500 nomes, no total, cobrindo o período de 1961 a 2001. A pesquisa tem como pressupostos que os nomes próprios são caracterizados por apresentar lema e função de nome próprio (LANGENDONCK, 2007) e serem resultado de uma escolha consciente por parte do designador da qual resulta um fato onomástico cuja análise requer estudos interdisciplinares. Os resultados mostram uma diminuição da escolha de nomes por motivo religioso, a qual não está relacionada a uma diminuição na religiosidade, mas, sim, a mudanças no conceito de identidade religiosa.

Palavras-chave: Onomástica; antroponímia; identidade religiosa.

Abstract: This paper investigates proper name's choice for religious motives in Marechal Cândido Rondon, a city located on the West side of the state of Paraná in the South of Brazil. This research is based on three corpora: one collected in 2012 from reports of $2^{\text {nd. }}$-year students of Letters; another collected in 2013 from questionnaires given to $4^{\text {th }}$-year students of Letters; and a sample of 500 birth certificates from 1960 to 2000 . The article assumes the point of view that anthroponymy is characterized by presenting lemma and function for the first name's choice (LANGENDONCK, 2007); therefore naming is a result 
of a conscious choice by the designator, which generates an onomastic fact that requires interdisciplinary studies to be analyzed. The results show a reduction on choices of names for religious motives, and also that this is not related to a decrease in religiosity, but rather to changes in religious identity conception.

Keywords: Onomastics; anthroponymy; religious identity.

Recebido em: 15 de outubro de 2014. Aprovado em: 25 de maio de 2015.

\section{Introdução}

A pesquisa descrita ao longo deste artigo se inscreve na Onomástica, área da Linguística que se dedica ao estudo dos nomes próprios. Uma de suas áreas de estudo é a Antroponomástica, voltada ao estudo dos nomes próprios de pessoas, os antropônimos. Um dos artigos mais antigos sobre antropônimos a que se tem acesso pelo Portal de periódicos da CAPES (Coordenação de Aperfeiçoamento de Pessoal de Nível Superior) foi publicado em 1930. Trata-se de uma investigação sobre a escolha de nomes próprios para os filhos numa comunidade negra de uma região dos Estados Unidos (HOLMES, 1930). Em seu artigo, Holmes cita uma tese de doutorado defendida em 1927. (MICHAELSSON, 1927 apud HOLMES,1930 p.464). Outro marco de início da área é a publicacão de Dalzat Les mons de personnes: origine et évolution, em 1925, citada em um texto que historiza o International Council of Onomastics Sciences (DE STEFANI, 2014, s/p).

Em língua portuguesa, o estudo dos nomes próprios de pessoa começou por iniciativa de Leite de Vasconcelos "quem, pela primeira vez, em 1887, empregou o termo <<Antroponímia>>" (DICK, 1992, p. 179) para se referir ao conjunto de antropônimos, isto é, nomes próprios de pessoa.

A investigação ora apresentada se inscreve na Antroponomástica; utiliza metodologias qualitativas de pesquisa e adota uma perspectiva interdisciplinar, haja vista que a investigação apresentada, ao relacionar os estudos sobre religião, religiosidade e identidade aos estudos sobre 
motivações para a escolha antroponímica instaura "um $<<$ segundo nível $>>$ de colaboração entre disciplinas diversas, ou entre setores heterogêneos de uma mesma ciência que conduz a interações propriamente ditas, isto é, certa reciprocidade dentro das trocas, de maneira que aí haja um total enriquecimento mútuo" (ALVARENGA et. al. 2011, p. 36-37).

Contudo, considerando a diferença existente entre disciplinasmeio e a disciplina-fim em Onomástica, o fim das investigações concerne ao nome próprio. Para se entender o fenômeno onomástico, porém, não é suficiente proceder à descrição linguística, são necessárias contribuições de outras áreas do conhecimento, como a História, a Geografia, a Sociologia e a Antropologia, entre outras. Em cada uma dessas áreas, pode haver estudiosos que estudam os nomes próprios, porém, não como um fim, mas, sim, como um meio pelo qual se consegue investigar melhor outro objeto de estudo. Sabe-se, por exemplo, que muitos antropólogos se dedicam ao estudo do nome próprio como um meio para conhecer melhor certas características de um dado grupo social.

O presente artigo tem por escopo estudar a escolha de nomes próprios de pessoa (os antropônimos) por motivação religiosa em Marechal Cândido Rondon, município situado no oeste do estado do Paraná, e investigar se os fatos antroponímicos observados estão relacionados a mudanças ocorridas no âmbito religioso tanto no nível nacional, quanto no nível regional. Não se trata, contudo, de estudar o fato linguístico como indício de mudanças no âmbito religioso, sendo essas objeto de estudo do antropólogo e do teólogo.

Há antropônimos cujo significado remete diretamente à religião. Nomes como Maria, José, Jesus e Mateus são nomes com conotação religiosa. Maria de Lourdes é um nome duplo que aponta para a tradição católica de se escolher um nome segundo o calendário litúrgico, caso a pessoa chamada Maria de Lourdes tenha nascido no dia da santa, 11 de fevereiro, e a pessoa que assim designou a recém-nata o tenha escolhido para prestar homenagem à santa do dia.

Se bem que o caráter religioso desses nomes esteja relacionado aos significados que os nomes apresentam no contexto cristão e católico do qual o Brasil faz parte, não há nada que garanta que uma pessoa 
chamada José o seja em decorrência de uma escolha motivada pela religião, pois o significado do nome pode ser divergente da motivação pragmática que resultou na escolha antroponímica. Percebe-se, pelo exemplo dado, a diferença existente entre o estudo do significado do nome e a investigação dos motivos que resultaram na escolha de um nome para designar um indivíduo.

Langendonck distingue o estudo do significado etimológico de um nome próprio do estudo de seus usos para dar conta tanto de usos que transformam um nome próprio em nome comum quanto de usos que transformam nomes comuns em nomes próprios (LANGENDONCK, 2007, p. 7-9, 84-102). Assim, por exemplo, os nomes próprios Tânia e Tatiane, analisados como lema, são nomes russos, o segundo uma forma diminutiva do primeiro. Se o que se leva em consideração é a função nome próprio, o nome Tânia apresenta função de nome próprio na frase "Eu vi a Tânia hoje", mas não na frase: "Conheço muitas Tânias" que, no caso, significa que o enunciador conhece muitas pessoas chamadas Tânia, não havendo a referencialidade unívoca que caracteriza a função de nome próprio. Em palavras homônimas podem ser encontrados exemplos de que um mesmo nome pode ou não ser usado em função de nome próprio: a palavra "rosa" é nome comum se designa nome de flor, e um nome comum em função de nome próprio quando é usado para fazer referência a uma mulher.

O lema de um nome próprio, por sua vez, pode ou não ser levado em conta por aquele que escolhe o nome próprio para nomear outrem. Exemplificando a primeira alternativa, pode-se imaginar o caso hipotético de uma moça que se chama Rosa porque seu pai o escolheu por achar a filha parecida com uma rosa. Ilustrando a segunda alternativa, a moça chamada Rosa foi assim chamada por seu pai querer homenagear outra pessoa chamada Rosa.

Com base nas distinções entre lema de nome próprio, função de nome próprio e motivação para a escolha antroponímica, entende-se melhor o objeto de estudo da pesquisa ora apresentada: se os nomes próprios que apresentam lema religioso, apresentam motivação religiosa, isto é, se foram escolhidos pelos pais em virtude de seu lema. Tratando dessa questão, nesse artigo, são apresentados resultados de um estudo que investigou quantos nomes pretensamente religiosos têm sido 
escolhidos em Marechal Cândido Rondon, e se esses nomes resultam de uma motivação religiosa por parte de quem os escolheu.

A investigação está respaldada por dados oriundos de três fontes: corpus formado por certidões de nascimento de pessoas nascidas no município de 1961 a 2001 (500 registros), corpus formado por relatos narrativos escritos por acadêmicos do segundo ano curso de Letras da Unioeste de Marechal Cândido Rondon (23 relatos escritos em 2012) e corpus formado por questionários respondidos por acadêmicos do quarto ano do curso de Letras da mesma universidade (19 questionários preenchidos em 2013). Cumpre informar que a população atual do município, segundo o último IBGE publicado, é de 50.229 munícipes (IBGE, 2010). Nas análises baseadas nos dados do IBGE, apresentam-se os dados por percentuais e não pelo número de pessoas entrevistadas, procedimento que torna comparáveis os dados ao longo do eixo cronológico, não obstante a evolução populacional do município.

Numa primeira etapa, foram selecionados nomes que apresentam lema religioso nos corpora de 2012 e 2013. Na segunda etapa, foi analisado o significado etimológico e / ou enciclopédico dos lemas segundo informações do dicionário onomástico de Guérios (1981). Na sequência, foi investigada a utilização deste elenco de nomes num corpus mais amplo formado por 500 certidões de nascimento. Então, as motivações citadas nos relatos de 2012 e nos questionários de 2013, para os nomes que apresentam lema religioso foram analisados. Por fim, pesquisas e análises oriundas de outros campos do conhecimento foram utilizadas para melhor entendimento dos resultados obtidos. Nesta última etapa investigativa, foram utilizados os censos de 1960 e de 2010 publicados pelo IBGE, pesquisas realizadas por um padre católico (ANTONIAZI, 2004) e as desenvolvidas por um antropólogo (BRANDÃO, 2004), além dos estudos de Hall sobre o descentramento da identidade (HALL, 2006).

\section{Nomes próprios que apresentam lema religioso}

Os dados mais recentes foram coletados em 2013, mediante questionários aplicados aos alunos do quarto ano de Letras. Para a 
análise, levou-se em consideração o significado etimológico e se os nomes estavam relacionados ao cristianismo. Ao todo, foram coletados dezoito questionários, cada um trazendo informações que o portador do nome sabia sobre o seu próprio nome. Do elenco de 18 nomes, todos femininos, 7 apresentam lemas religiosos: Aline Cristina, nascida em 1993; Andreia Regina, nascida em 1987; Daiane Maria, nascida em 1990; Fernanda Maria, nascida em 1985; Gabriela Cristina, nascida em 1988; Lucimara Teresinha, nascida em 1992 e Mariana, nascida em 1988.

A conotação religiosa desses lemas é atestada por Guérios, de seu dicionário de nomes e sobrenomes (1981) e / ou pelo conhecimento socialmente compartilhado sobre a Bíblia e o cristianismo. O nome Cristina provém do diminutivo latino Christinus (GUÉRIOS, 1981, p. 97), isto é, relativo a Cristo. O nome Teresinha remete à Santa Teresinha de Jesus, nascida em 1873 e falecida em 1897 (GUÉRIOS, 1981, p. 236). Guérios não aponta um só étimo para explicar a origem do nome Maria (GUÉRIOS, 1981, p.171), contudo, é notório que esse nome remete ao nome da mãe de Jesus Cristo; com relação ao nome Mariana, afirma ele que se trata de um nome composto, formado pela união dos nomes Maria e Ana (GUÉRIOS, 1981, p. 171). Regina, por fim, vem da palavra latina regina, que significa rainha, e é utilizado para referir-se à Nossa Senhora (GUÉRIOS, 1981, p. 210).

Outro corpus foi formado por narrativas pessoais escritas por acadêmicos do segundo ano de Letras, em 2012. Nessas narrativas, os portadores dos nomes contam o que eles acreditam serem as motivações para a escolha de seus nomes. Do elenco de 23 nomes, 8 remetem ao cristianismo, são eles: Ana Paula, nascida em 1985; Paula, nascida em 1991; Chrystine, nascida em 1992; Michele Cristina, nascida em 1989; Lygia Cristina, nascida em 1982; Pâmela Cristina, nascida em 1993; José Valdiney, nascido em 1980; e Rosane de Fátima, nascida em 1992.

Enquanto José tem conotação religiosa, por remeter ao pai de Jesus Cristo, Paula apresenta lema religioso por remeter ao apóstolo Paulo e Ana, por ser o nome da mãe de Maria de Nazaré, canonizada como Santa Ana. O nome Fátima, se bem seja etimologicamente um nome árabe, segundo Guérios, teve sua popularidade devida "às 
aparições de Nossa Senhora do Rosário (1917) na localidade Fátima, em Portugal (Nossa Senhora de Fátima)" (GUÉRIOS, 1981, p. 118).

A verificação dos nomes ora elencados no corpus mais amplo, formado por certidões de nascimento dos anos de 1961 a 2001, totalizando 500 nomes de recém-natos, fornece indícios sobre a frequência de utilização desses nomes ao longo do tempo na região. Ressalve-se, porém, que nem todos os alunos consultados são naturais de Marechal Cândido Rondon, fato que explica a ausência de alguns nomes no corpus formado por amostragem de certidões de nascimento. A Tabela 1 a seguir informa a frequência dos nomes, as décadas em que foram registrados e seu estatuto no sintagma formado pelo nome próprio completo, isto é, se o nome é prenome único (n.u.), primeiro nome (n.1) ou segundo nome (n.2). Cumpre esclarecer que as variantes gráficas foram lematizadas segundo a forma padrão, tendo em vista que, conforme relata a portadora do nome, Crystine é uma variante de Cristina.

Tabela 1 - Frequência dos lemas religiosos no corpus de Marechal Cândido Rondon

\begin{tabular}{llllll}
\hline Nome & 1961 & 1971 & 1981 & 1991 & 2001 \\
\hline Ana & Zero & zero & $2(\mathrm{n} 1)$ & Zero & $3(\mathrm{n} 1)$ \\
Paula & Zero & zero & $1(\mathrm{n} 1) 1(\mathrm{n} 2)$ & $1(\mathrm{n} 1)$ & Zero \\
Cristina & Zero & zero & $1(\mathrm{n} 1) 5(\mathrm{n} 2)$ & $6(\mathrm{n} 2)$ & $2(\mathrm{n} 2)$ \\
Fátima & Zero & zero & Zero & Zero & Zero \\
Maria & $6(\mathrm{n} 1) 3(\mathrm{n} 2)$ & $2(\mathrm{n} 1) 2$ & $1(\mathrm{n} 2)$ & Zero & $1(\mathrm{n} 1) ; 3$ \\
& & $(\mathrm{n} 2)$ & & & $(\mathrm{n} 2)$ \\
Mariana & Zero & zero & Zero & Zero & Zero \\
Teresinha & $1(\mathrm{n} 2)$ & $2(\mathrm{n} 2)$ & Zero & $1(\mathrm{n} 2)$ & Zero \\
José & $1(\mathrm{n} 1) 2(\mathrm{n} 2)$ & $2(\mathrm{n} 1)$ & Zero & $1(\mathrm{n} 2)$ & Zero \\
\hline
\end{tabular}

Fonte: a autora.

Os dados do corpus de Marechal Cândido Rondon dão indícios da utilização de cada nome no município. O nome Paula é o menos utilizado de todos, o foi por apenas duas décadas. O nome Ana foi mais utilizado, e, assim como Paula, em décadas alternadas. O nome Teresinha também foi pouco utilizado, tendo sido registrado apenas nas décadas de 60 e 70 do século passado. O nome Cristina, por sua vez, teve seu auge em 1981 e 1991, indicando ter sido adotado por modismo. 
O nome Maria destaca-se: só não foi usado na década de 90 do século passado, indicando ser este um nome tradicional na região. O nome José, por sua vez, por ter sido utilizado por três décadas é, na região, menos tradicional que Maria.

É importante observar que há bastante correlação entre os nomes dos alunos e os nomes coletados por amostragem de certidões de nascimento. Dos doze nomes de alunos analisados poucos não apresentam correspondência com os dados coletados em cartórios. Todas as ocorrências de Cristina nos corpora acadêmicos são de pessoas nascidas nas décadas de 1980 e 1990, as mesmas em que houve utilização desse prenome no corpus de Marechal Cândido Rondon. Mesmo para Paula, nome pouco utilizado, houve corroboração, já que as alunas chamadas Paula nasceram na década de 90 quando também houve registro desse prenome nas certidões de nascimento. Isso não ocorreu com os prenomes José e Teresinha, cujos portadores nasceram em décadas nas quais não houve registro de seu uso na amostragem de certidões. Outra discrepância é a ausência, no corpus mais amplo, dos nomes Mariana e Fátima. Percebe-se, assim, que os nomes dos alunos, quase sempre, são nomes em uso no município, o que evidencia não só a representatividade da amostragem de certidões mas também a possibilidade de, com base nos dados coletados no meio acadêmico, se fazer generalizações sobre a antroponímia da região.

Considerando a totalidade dos nomes de alunos que apresentam lema religioso e comparando-se os números de ocorrência dos mesmos nomes no corpus de Marechal Cândido Rondon, percebe-se uma tendência de manutenção da frequência de nomes com conotação religiosa: no corpus do município, esses nomes correspondem a 34,\% do total; nos corpora de 2012 e 2013, a média de utilização foi de $30,25 \%$ (34,8\% em 2012 e $25,71 \%$ em 2013).

Será que esta continuidade de utilização indica uma manutenção na religiosidade daqueles que escolheram os nomes dos alunos pesquisados, marcando isso um sinal de conservadorismo? Será que o significado etimológico de um nome pode trazer informações sobre a motivação que levou à sua escolha? Ou, em outras palavras, será que um nome que apresenta lema religioso é escolhido, em detrimento de outros, por ser religioso? Na seção seguinte, apresentam-se os dados relativos às 
motivações citadas pelos portadores para explicar a escolha do nome por parte dos pais.

\section{Motivações para a escolha de nomes próprios pretensamente religiosos}

A análise dos relatos dos portadores dos nomes, ao contrário daquilo que a análise dos lemas indica, demonstrou que houve escolha de lemas religiosos por outros motivos. Por exemplo, o nome Crystine, variante de Cristina, foi escolhido por motivações estéticas, pois, conforme afirma a portadora, o pai escolheu esse prenome "por causa da sonoridade "ist" e "Crist" que, para ele, é uma composição de sons chamativa".

Em seu relato, Michele Cristina não informa nenhuma motivação para a escolha do segundo nome. Ela comenta somente sobre o seu primeiro nome, o que pode ser um indício de que apenas esse seja utilizado. O mesmo ocorreu no relato de Pâmela Cristina.

Lygia Cristina, ao contrário, conta que seu segundo nome foi escolhido por haver uma "tradição de família, na qual a primeira filha deveria ter Cristina no nome". Ela disse que a tradição foi estabelecida por sua avó chamada Erna Cristina (provavelmente nascida no Rio Grande do Sul, tendo em vista a história de colonização da região) "por pedido ou ordem, todos os filhos cumpriram a tradição".

A homenagem familiar foi também a motivação que levou à escolha do nome José como segundo nome: "José foi dado para homenagear meu pai - José (...)-, que o recebeu para homenagear São José." Interessante notar que o nome do homenageado, mas não do portador, é que foi escolhido por motivo religioso, dado cuja análise será feita na seção seguinte. Outra homenagem familiar ocorreu na escolha do nome Paula e para a escolha de Paula como segundo nome, de acordo com a portadora do nome Ana Paula.

No corpus de 2012, apenas dois nomes foram realmente escolhidos por motivação religiosa. Conforme relato da portadora do nome Rosane de Fátima, "minha mãe acrescentou o nome do meio - de

\footnotetext{
${ }^{1}$ Para manter o anonimato dos sujeitos não serão feitas referências bibliográficas dos relatos, para não informar o nome completo das pessoas citadas.
} 
Fátima - porque nasci no dia 13 de maio, dia de nossa Senhora de Fátima". A escolha do nome Ana também foi norteada por motivos religiosos. A portadora do nome conta que ele foi escolhido por sua tia, após saber que "a mãe de Maria, avó de Jesus, tinha o nome de Ana".

Nos questionários coletados em 2013, observaram-se os mesmos fenômenos ora descritos. Nome com lema religioso na segunda posição não foi comentado nem por Andréia Regina, nem por Daiane Maria, nem por Gabriela Cristina. Há também registro de escolha por motivo estético. Lucimara Terezinha informa no questionário: "meus pais contam que o meu nome e dos meus irmãos foi escolhido porque acharam o nome bonito"; Mariana diz apenas que o seu nome foi escolhido por a mãe dela gostar do nome desde que ela era adolescente. Também houve uso de segundo nome de lema religioso para homenagear familiares. Aline Cristina conta que o segundo nome foi escolhido por ser o nome de sua mãe; Fernanda Maria informa que seu nome faz homenagem aos avós maternos, Ferdinando e Maria.

Com relação ao nome Maria, é digno de nota ele fazer parte de nomes duplos em todas as ocorrências de todos os corpora. Esse uso remete à crença de que seria desrespeitoso chamar alguém utilizando apenas o nome da mãe de Jesus, tabu que se resolvia pela escolha de nomes compostos como Maria Rosa, Maria Antônia, Maria da Conceição, etc. (DICK 1992, p. 194). Nota-se, contudo, uma diferença entre usos: enquanto o uso tradicional tornava o nome Maria um primeiro nome, nos usos de 2013, o nome Maria ocupa a segunda posição, e nenhum deles foi escolhido por motivação religiosa.

Os resultados obtidos pela análise das motivações dos nomes que apresentam lema religioso mostram que, dos 15 nomes supostamente religiosos, apenas dois foram escolhidos em virtude do significado de seu lema. Esse fenômeno pode ser datado, conforme a data de nascimento dos portadores, como tendo início na década de 1980 e se acentuando a partir de 1990.

A seção seguinte propõe uma hipótese explicativa para o fato antroponomástico do desuso de escolha antroponímica por motivo religioso, bem como investiga a identidade religiosa. 


\section{Nome, Identidade e Identidade religiosa}

Escolher um nome para um filho sinaliza um desejo de identidade para o recém-nato. Assim, a escolha de um nome frequente numa dada comunidade pode sinalizar o desejo dos pais de inserir o filho nessa comunidade, o que pressupõe certo compartilhamento de valores. Numa família na qual os pais são migrantes num país estrangeiro, pode haver a escolha de um nome comum na comunidade de origem dos pais, atitude que indicaria uma identificação com a cultura e os valores dos pais; ou, então, pode ser dada preferência por um nome bem aceito no país que recebeu a família. Também pode haver escolha de nomes neutros, universais ou cosmopolitas, que possam pertencer a ambas as culturas; ou mesmo a escolha de dois nomes: um referendando a cultura de chegada, e outro, a cultura de partida.

Essa relação entre a escolha do antropônimo e a identidade desejada pelos pais foi mostrada pela pesquisadora sueca Emilia Aldrin (2007), assim como outros autores. A autora fez uma enquete com pais de crianças nascidas em Gothenburg, na Suécia, entre maio e junho de 2007. As famílias responderam a um questionário enviado pelo correio pela pesquisadora. Elas foram divididas em dois conjuntos: um formado por famílias monolíngues e suecas; outro formado por famílias multilíngues, nas quais um ou ambos os pais falavam, pelo menos, outra língua além do sueco, tendo um ou ambos nascido em outro país. Com relação às famílias multilíngues, $68 \%$ delas escolheram nomes considerados normais para os suecos e as demais escolheram nomes vistos, pelos suecos, como estrangeiros (ALDRIN, 2007, p. 4).

Enquanto a primeira escolha sinaliza a intenção de integrar o filho na cultura local, a segunda sinaliza a intenção ou de se manter fiel às culturas de origem, ou de atribuir ao filho uma identidade cosmopolita, nos casos em que o nome escolhido tampouco era típico dos países de origem dos pais. Como aponta Aldrin:

Diferentes escolhas de nomes podem significar a construção de identidades étnicas diferentes para a 
criança. Mediante a escolha de um nome tipicamente sueco, ou um nome que é típico de outra cultura, ou um nome que é comum a ambas as culturas, ou um nome que não é comum a em nenhuma delas, os pais estabelecem uma base pela qual a criança irá perceber-se a si mesma: como essencialmente sueca, como essencialmente "estrangeira", ou como nenhuma delas. O nome é também um sinal para os outros sobre quem a criança é, em termos de identidade étnica e de filiação a um grupo étnico. (ALDRIN, 2007, p. 3, tradução nossa). ${ }^{2}$

Utilizando esse raciocínio para o que concerne a identidade religiosa, pode-se afirmar que a escolha de um nome apresentando lema religioso em virtude de seu significado etimológico, por partes dos pais, é uma maneira de assinalar a identidade religiosa da família e inscrever o filho neste mesmo âmbito religioso.

Este raciocínio só é válido, caso se conceba a noção de identidade como algo fixo, racional e imutável. Nesse contexto, por exemplo, se uma pessoa nasce numa família católica, torna-se católica, identidade religiosa que se mantém durante toda sua vida. Nesse caso, a escolha de nome por motivo religioso é uma maneira de sinalizar e indicar a identidade religiosa pretendida pelos pais. Dessa forma, surgem duas hipóteses explicativas iniciais: ou há um decréscimo na identificação das pessoas que vivem em Marechal Cândido Rondon com a religiosidade, ou a expressão da identidade religiosa não tem sido feita mediante a escolha antroponímica, mas, sim, por outros meios.

Para averiguar essas hipóteses, investigamos as mudanças ocorridas no âmbito religioso desde 1960 até os dias de hoje, no Brasil e em Marechal Cândido Rondon. Assim, como já dissemos, foram

${ }^{2}$ Different name choices may mean the construction of different ethnic identities for the child. Through choosing a typically Swedish name, or a name that is typical of another culture, or a name that is common to both cultures, or a name that is common to neither of them parents can lay a foundation for how the child will perceive him- or herself: as primarily Swedish, primarily "foreign", or both or neither. The name is also signal to others who the child is in terms of ethnic identity and ethnic group membership (ALDRIN, 2007, p. 3). 
analisados dados oriundos dos Censos do IBGE de 1960 e de 2010, com análise aprofundada baseada nos dois artigos dedicados ao tema: o de um do antropólogo (BRANDÃO, 2004), outro de um padre católico (ANTONIAZI, 2004). A análise das mudanças ocorridas no âmbito religioso se baseou na comparação dos dados oriundos desses dois censos. Cumpre ressaltar que as características de cada censo já indicam diferenças importantes a respeito de como a identidade religiosa é concebida.

No censo de 1960, há oito categorias relativas ao tópico. No relatório, os autores explicam: "discriminaram-se aquelas que congregavam maior número de adeptos no país (IBGE, 1960, p. 13). Além disso, observando-se as tabelas, percebe-se que pessoas de todas as faixas etárias foram incluída nos cálculos, o que significa que os menores de idade tiveram sua identidade religiosa estabelecida pela pessoa entrevistada. Deve ter havido o seguinte: numa família formada por um casal e três filhos, o entrevistado ou o censor considerou que, sendo os pais de uma religião, toda a família compartilha a mesma identidade religiosa, pensamento que revela uma concepção fixa e estável de identidade religiosa.

No censo de 2010, há 22 categorias, muitas delas discriminadas em subcategorias indicando uma multiplicidade de alternativas e um aumento significativo da diversidade religiosa no país. Para os cômputos, levou-se em consideração apenas a escolha religiosa do entrevistado. Além disso, o fato de haver uma alternativa chamada "religião não definida ou múltiplo pertencimento" indica que foi considerada a possibilidade de haver indivíduos religiosos, porém sem religião, e de sujeitos que compartilham mais de uma crença religiosa. Essas características do censo mais recente são sinais de que a definição subjacente de identidade religiosa adotada não é a mesma adotada em 1960. Atualmente, a identidade religiosa parece ser vista como algo pessoal, fruto de escolha individual e passível de se modificar.

Não obstante as peculiaridades de cada censo, é válido cotejar os dados, cotejo possível quando são feitas algumas adaptações das categorias utilizadas em cada um. Na tabela a seguir, nota-se que os designados como protestantes em 1960 correspondem aos que hoje em dia são considerados evangélicos, e a categoria daqueles que não têm 
uma religião determinada, ou pertencem a mais de uma, foi equiparada com aqueles que, em 1960, declararam não ter religião.

A comparação que a Tabela 2 visualiza mostra uma diminuição significativa de católicos e aumento de fiéis em religiões evangélicas. Os aumentos mais drásticos estão entre aqueles que não têm religião e aqueles que declaram não pertencer a uma religião definida. Esses últimos dados revelam uma tendência geral à laicização da sociedade, na qual está deixando de ser um tabu ou um estigma não ter uma religião definida ou assumir não ter religião. Uma análise mais minuciosa de dados relativos a Marechal Cândido Rondon revela se as tendências observadas em termos nacionais estão presentes no município.

Tabela 2 - Censo IBGE Religião 1960 E 2010 Brasil

\begin{tabular}{ll}
\hline \multicolumn{1}{c}{ IBGE1960 } & \multicolumn{1}{c}{ IBGE 2010 } \\
\hline Católicos $91,21 \%$ & Católicos 64,83\% \\
Protestantes 5,30\% & Evangélicos 22,26\%; Evangélicos luteranos 0,52\%. \\
Sem religião 0,38\% & Sem religião 8,039\% \\
Sem declaração 0,039 & Não det. ou mult.pert.0,337\% \\
\hline
\end{tabular}

Fonte: compilação de dados do IBGE.

A Tabela 3 mostra a comparação dos dados nacionais com os dados do município. Chama a atenção os luteranos estarem numa posição marginal no país, mas, na região, ocuparem a segunda posição em número de fiéis.

Tabela 3 - Censo IBGE Religião Brasil 1960 e Marechal Cândido Rondon em 2010

\begin{tabular}{l|l}
\hline IBGE 2010 & IBGE 2010 para Mal. C. Rondon \\
\hline Católicos $64,83 \%$ & Católicos $56,21 \%$ \\
Evangélicos,22,26\% & Evangélicos $38,85 \%$ \\
Evangélicos luteranos $0,52 \%$. & Evangélicos luteranos. $25,11 \%$ \\
Sem religião $8,039 \%$ & Sem religião $2,06 \%$ \\
Não det. ou mult. pert. $0,337 \%$ & Não det. ou mult. pert. $0,221 \%$ \\
\hline
\end{tabular}

Fonte: compilação de dados do IBGE.

Segundo o censo de 2010, de cada cinco munícipes, um é luterano. Essa proporção explica-se pelo fato de o município ter sido 
colonizado, principalmente, por gaúchos de ascendência germânica muitos dos quais luteranos. Segundo Antoniazi:

[e]ntre os protestantes que chegaram ao Brasil, depois de pequenos grupos de anglicanos (ou episcopais), ligados à presença inglesa após 1810, os imigrantes mais numerosos foram luteranos de origem alemã. As duas primeiras comunidades da hoje Igreja Evangélica de Confissão Luterana no Brasil (IECLB) foram constituídas em Nova Friburgo (RJ) e São Leopoldo (RS), em 1824. "A IECLB tem sido considerada igreja de etnia, igreja de alemães e seus descendentes" (MENDONÇA, 1989, p. 54). (ANTONIAZI, 2004, p. 27, grifo nosso).

Os dados indicam que as tendências nacionais também se fazem presentes, porém, em menor grau. O percentual de pessoas que assumem não terem religião no município é quatro vezes menor do que no país, contudo, a tendência a não ter religião determinada, ou de professar mais de uma religião, mantém-se com poucas alterações.

Os dados do IBGE mostram, e a história da região confirma, que há mais luteranos e menos católicos no município em comparação com o resto do país. Além disso, parece haver uma tendência à manutenção maior da religiosidade em decorrência do menor número de pessoas sem religião. Para saber se, realmente, há conservadorismo religioso, neutralizou-se a desproporção local entre luteranos e católicos, incluindo-os numa mesma categoria em todos os censos, para fins de comparação, conforme mostra a Tabela 4.

Tabela 4 - Religiões majoritárias no Brasil e em Mal. Cândido Rondon

\begin{tabular}{l|l|l}
\hline IBGE 1960 & IBGE 2010 BRASIL & $\begin{array}{l}\text { IBGE 2010 Mal. C. } \\
\text { Rondon }\end{array}$ \\
\hline Cat. e Evang. 96,51\% & Cat. e Evang. 87,09\% & Cat. e Evan. 95,06\% \\
Sem religião 0,38\% & Sem religião 8,039\% & $\begin{array}{l}\text { Sem religião 2,16\% } \\
\text { Sem decl. 0,039\% }\end{array}$ \\
& $\begin{array}{l}\text { Não det. ou mult. pert. } \\
0,337 \%\end{array}$ & $\begin{array}{l}\text { Não det. ou mult. pert. } \\
0,221 \%\end{array}$ \\
\hline
\end{tabular}

Fonte: compilação de dados do IBGE. 
Essa última comparação evidencia a manutenção das crenças no município desde a época em que foi criado na década de 1960: a proporção de fiéis das religiões hegemônicas praticamente não se alterou. À luz desses resultados, a hipótese explicativa inicial segundo a qual a diminuição de nomes escolhidos por apresentarem lema religioso seria decorrente de um decréscimo na identificação das pessoas com a religiosidade foi refutada. Cumpre, então, investigar a segunda hipótese: a expressão da identidade religiosa não está mais sendo expressa pela escolha de nomes religiosos para os filhos.

Para a investigação dessa hipótese, as práticas nomeadoras citadas pelo aluno Valdiney José, nascido em 1980, são emblemáticas. O nome de seu pai, provavelmente nascido entre 1950 e 1960, foi escolhido para homenagear São José. Trata-se de uma escolha parental que caracteriza o filho como identificado pela religião católica. Subjaz a essa escolha a crença de que a religião dos pais é e será a religião dos filhos, concepção também adotada pelo censo de 1960 . O nome do filho, por sua vez, foi escolhido para prestar homenagem ao pai, e não ao santo. Essa escolha inscreve o nomeado como pertencente à família, sem identificar ou sinalizar a religião do filho.

Essa opção, por não determinar a religião do filho, pressupõe outra relação com a religião e com a religiosidade: trata-se do ponto de vista segundo o qual a religião é uma escolha individual, escolha que pode dar-se com base num elenco cada vez mais amplo de alternativas e que pode ser também uma escolha provisória, haja vista haver, hoje em dia, a possibilidade de um indivíduo mudar de religião várias vezes ao longo de sua vida.

Ambas as concepções de identidade religiosa são assim apontadas e descritas por Brandão:

Desde uma ótica do ator cultural, mais do que da instituição social, isto tem a ver com todo um processo bastante atual de individualização que, com o atraso de vários anos chega, afinal, também à América Latina. Em síntese, uma dívida de crença do sujeito para com instituições que começam com a sua família e podem terminar com a sua pátria, pensada e 
vivida através da religião, tende a tornar-se o seu oposto. Isto é, tende a converter-se em um direito de $f_{e}$ franca e crescentemente individualizado (BRANDÃO, 2004, p. 281).

Com a análise de Brandão, entende-se melhor o que mudou na identidade religiosa dos brasileiros e dos habitantes de Mal. C. Rondon. Quando o pai de Valdiney José nasceu, a crença era uma dívida a ser saldada na família ou no país. Se a família é católica, os fillhos devem ser católicos, identidade a ser mantida por toda a vida. No caso específico dos cidadãos de Mal. C. Rondon com ascendência germânica, a família deve ser e se manter luterana. Na época do nascimento de Valdiney José, o cenário religioso brasileiro já estava se modificando. Desde então, a fé começa a ser vista também como um direito individual, possibilitando a existência do ponto de vista segundo o qual os pais não devem impor aos filhos sua própria religião. Desse modo, os filhos devem fazer, individualmente, sua opção religiosa, está aí um possível motivo para os pais evitarem a escolha de um nome de lema religioso.

Outro motivo factível, possivelmente de surgimento recente, vem da percepção de que a escolha feita pode não se manter durante toda a vida de uma pessoa. A percepção da escolha de crença como algo provisório faz parecer desaconselhável vincular $\mathrm{o}$ filho, desde $\mathrm{o}$ nascimento, a uma religião determinada, a qual o filho possa, no futuro, abandonar. Conforme explica Brandão,

uma certa, relativa e sempre não previsível lógica de mercado vivida como experiência cultural da buscade-sentido-de-vida-através-da-fé, faculta a que as pessoas possam se relacionar com a religião de uma tal maneira que, ao mesmo tempo e (...) a um só momento de suas vidas, elas se reconheçam partilhando mais de um sistema religioso. Vivendo a experiência pessoal de dirigir a vida segundo os valores e as sensibilidades de mais de uma religião, sem se reconhecerem necessariamente fiéis a uma única. Ainda que esta possibilidade não seja por agora a norma, há uma tendência crescente a que as pessoas creditem um amplo e generoso valor potencial do 
sagrado a todas as religiões de seu campo visível de escolhas. E, ao pensarem assim, optem por relacionarse com algumas delas, de acordo com a lógica pessoal de suas próprias necessidades, sentindo-se, no limite, vinculadas a duas ou mesmo três delas a um só tempo ou entre movimentos pendulares de adesão provisória (BRANDÃO p. 280).

Ressalte-se que a possibilidade de escolher entre várias religiões ao longo da vida e, quantas vezes for necessário, torna a identidade religiosa algo fluído, instável. Tem-se, assim, o descentramento da identidade (HALL, 2006) atuando no âmbito religioso e resultando no estado atual de mobilidade e multiplicidade religiosas observada nacionalmente e, em menor grau, em Marechal Cândido Rondon, onde se constatou o decréscimo de escolha antroponímica por motivo religioso.

\section{Considerações finais}

Esta pesquisa investigou em que medida nomes que remetem ao universo religioso cristão foram escolhidos pelos pais dos portadores desses nomes em Mal. C. Rondon em virtude da religiosidade professada por eles. A análise dos relatos e das respostas dos alunos mostrou que uma parte ínfima dos nomes que apresentavam significado religioso foi escolhida por assim o serem.

Tal resultado confirma a existência de dois modos diferentes de se estudar os nomes próprios: enquanto nome cujo significado está atrelado ao seu étimo; e fruto de uma escolha consciente e motivada que se encontra no ato de designação atribuidora do nome a um indivíduo no mundo, ato cuja motivação requer investigação.

A constatação de que a motivação religiosa para a escolha de nomes é cada vez mais infrequente ensejou pesquisas complementares para averiguar se essa diminuição era devida a certa laicização da comunidade, ou a mudanças relativas à identificação religiosa. Estudos realizados sobre essa questão com base em dados censitários e análises teológicas e antropológicas mostraram que a decisão de se evitar escolher um nome religioso ao filho, indicando que a pertença religiosa 
pode ser explicada pela crença de que cada indivíduo deve ser livre para escolher a religião que professará.

Apesar de a pesquisa ter abrangido duas vertentes de estudo de nome próprio e ter sido suficiente para explicar o fato antroponomástico relacionando linguagem, cultura e sociedade, trata-se de uma investigação limitada, primeiro pela quantidade de relatos e questionários considerados, apenas 42; segundo, por apenas ter sido considerada uma das motivações citadas pelos alunos. Pesquisas amplas sobre a motivação religiosa na escolha de nomes e outras investigações focando os demais tipos de motivos que resultam na escolha antroponímica são ainda necessárias.

\section{Referências}

ALVARENGA, Augusta Theresa de. et. al. Histórico, fundamentos filosóficos e teórico-metodológicos da interdisciplinaridade. In: PHILIPPI JR., Arlindo; SILVA NETO, Antonio J. (Ed.). Interdisciplinaridade em ciência, tecnologia e inovação. Barueri, SP: Manole, 2011. p. 3-68.

ALDRIN, Emilia. The choice of firsts names as a social resource and act of identity among multilingual families in contemporary Sweden. In: INTERNATIONAL CONGRESS OF ONOMASTIC SCIENCES, $23^{\text {rd. }}$, August 17 to 22, 2007. York University, Toronto. Proceedings... Toronto, Canada, 2007. p. 86-92.

ANTONIAZI, Alberto. Por que o panorama religioso no Brasil mudou tanto? Horizonte, Belo Horizonte-MG, v. 3, n. 5, p. 13-39, 2º.sem. 2004.

BRANDÃO, Carlos Rodrigues. Fronteira da fé - Alguns sistemas de sentido, crenças e religiões no Brasil de hoje. Estudos Avançados, São Paulo, v. 18 (52), 2004.

DE STEFANI, Elwys. 2014. Notes on the history of ICOS. Disponível em: <http://www.icosweb.net/index.php/brief-history.html>. Acesso em: 7 out. 2014. 
DICK, M. de P. Toponímia e antroponímia no Brasil. Coletânea de estudos. $3^{\text {a }}$ ed. São Paulo: Serviço de Artes Gráficas da FFCLH/USP, 1992.

GUÉRIOS, Mansur. Dicionário Etimológico de nomes e sobrenomes. São Paulo: Editora Ave Maria, 1981.

HALL, S. A. Identidade cultural na pós-modernidade. Trad. Tomaz T. da Silva, Guacira L. Louro. 11 $1^{\text {a }}$ ed. Rio de Janeiro: DP\&A Editora, 2006. HOLMES, U. T. A study in Negro Onomastics. American Speech, v. 5, n. 6, p. 463-467, August, 1930. Disponível em: $<$ http://www.jstor.org/stable/452375>. Acesso em: 22 ago. 2013.

INSTITUTO BRASILEIRO DE GEOGRAFIA E ESTATÍSTICA IBGE. (Paraná). Censo Demográfico de 1960. Paraná. Disponível em: $<\mathrm{http} / / /$ biblioteca.ibge.gov.br>. Acesso em: 20 mar. 2014.

. Censo 2010. Mapa interativo. Variável religião por município. (Rio de Janeiro, RJ). Disponível em: <www.censo.ibge.gov.br/apps/mapa>. Acesso em: 20 mar. 2014.

LANGENDONCK, Willy Van. Theory and Typology of Proper Names. Berlim: Mouton de Gruyter, 2007.

MICHAELSSON, Karl. Etudes sur les Noms de Personne français d'aprés les Rôles de Taille Parisiens. Uppsala Universitet, Sweden, 1927. 